\title{
FORCED INTERVENTIONS AGAINST PERSONS WITH MENTAL DISORDERS - MEDICAL-LEGAL ACCENTS
}

\author{
V. Mihaylova ${ }^{1,2}$, M. Liochkova ${ }^{2}$, A. Alakidi ${ }^{3}$, K. Kazandjiev $^{4}$, D. Shopov $^{5}$ \\ ${ }^{1}$ Vanina Mihaylova, Department of Kinesitherapy, Faculty of Public Health, Medical University-Sofia, \\ Bulgaria \\ ${ }^{2}$ Department of Healthcare Management, Faculty of Public Health, Medical University-Plovdiv, \\ Bulgaria \\ ${ }^{3}$ Medicine Faculty, Medical University-Sofia, Bulgaria \\ ${ }^{4} \mathrm{III}^{\mathrm{Th}}$ District Police station-Plovdiv, Bulgaria \\ ${ }^{5}$ Department of Social Medicine and Public Health, Faculty of Public Health, \\ Medical University-Plovdiv, Bulgaria
}

\begin{abstract}
A brief analytical overview of the prescriptions for enforcement and the procedure for its implementation, respectively, Penal Code and Code of Criminal Procedure, as well as Instruction Nr. 1 for the activity of the health authorities in the placement of persons with psychiatric disorders in psychiatric hospitals under compulsory orders, as opposed to the compulsory accommodation and treatment with preventive purpose under the Health Act. Importance is attributed to Canadian Psychiatric Association-CPA (1980), which advocates a situation-based approach to this specific contingent, and Declaration of Helsinki (2000), to obtain adequate informed consent in cases of mental disorders by legally authorized representatives in accordance with the applicable law.

It is argued that coercive medication (including isolation, mechanical restraint, eventual electro-shock procedures, even neuroleptics, etc.) should only be taken when all means of informing people with mental retardation and aggressive behavioral abnormalities have failed, while strictly observing legislative restrictions. The bipolar nature between the doctor's responsibility to ensure the good / good of the patient from a medical point of view and the respect / respect for his will stands out as a fundamental bioethetical configuration.
\end{abstract}

Key words: aggressive behavioral abnormalities, coercive medication, legally authorized representatives, legislative restrictions, applicable law

\section{"No health without mental health"}

\section{WHO 2010}

The priority role in the ethics-deontology-law relation is assigned to morality. The emphasis on the moral element sets it as a "bridge" between the medical profession and legal regulation. The imperative of state coercion for the medical practitioner, in particular the psychiatrist - "you need", is clearly gravitating to the ethical "I must".

\footnotetext{
*Correspondence to: Vanina Mihaylova, Department of Kinesitherapy, Faculty of Public Health, Medical University Sofi; Department of Healthcare Management, Faculty of Public Health, Medical University Plovdiv, e-mail: vanina_delfi@abv.bg
}

They are highlighted on the basis of an analytical overview of the medical-legal aspect of researched sources and regulations for compulsory treatment and coercive interventions against persons with mental disorders, some guidelines for achieving better comfort and providing quality and modern medical assistance in psychiatric establishments.

The beginning of a qualitatively new health legislation in the Republic of Bulgaria, which treats the individual as a subject of inalienable human rights, was the ratification of the European Convention for the Protection of Human Rights and Fundamental Freedoms 
(promulgated SG 80/1992) (2). The courts were authorized to apply the international treaties entered into force for the Bulgarian state with priority over the internal legal norms which contradict them (Article 5, paragraph 4 of the Constitution) (3).

The requirement is that "No one can be subjected to forced treatment outside the cases provided for by law". Clinical distinctions
MIHAYLOVA $V_{\text {., et al. }}$ between compulsory and coercive treatment of socially ill patients are not fixed and commented, and in both cases Instruction No. 1 on the Activity of Health Bodies for the Placement of Persons in Psychiatric Hospitals (4). Medical-legal approaches to socially disturbed persons with psychiatric disorders are presented as follows:

\begin{tabular}{|l|l|l|l|}
\hline Subjects & $\begin{array}{l}\text { Indications for } \\
\text { accommodation and } \\
\text { treatment }\end{array}$ & $\begin{array}{l}\text { Legislative } \\
\text { regulations }\end{array}$ & $\begin{array}{l}\text { Implementation } \\
\text { procedures }\end{array}$ \\
\hline $\begin{array}{l}\text { In a state of sanity } \\
\text { without / before } \\
\text { committing a crime } \\
\text { with preventive } \\
\text { accommose-mandatory } \\
\text { station }\end{array}$ & $\begin{array}{l}\text { legislative } \\
\text { requirements under the } \\
\text { Health Act }\end{array}$ & $\begin{array}{l}\text { Health Act Ordinance } \\
\text { No. 16, (2005 of the } \\
\text { Health Insurance Act) } \\
\text { on Forensic } \\
\text { Psychiatric Expertise }\end{array}$ \\
$\begin{array}{l}\text { In a state of insanity } \\
\text { when a crime is } \\
\text { committed }\end{array}$ & forced accommodation & $\begin{array}{l}\text { under the Criminal } \\
\text { Code (CC) }\end{array}$ & $\begin{array}{l}\text { Penal Procedure Code } \\
\text { (PPC) }\end{array}$ \\
\hline
\end{tabular}

Therefore, under the Health Act (PHS), mandatory placement and treatment has a preventive purpose and is enforced against a person before committing a crime while the CCP enforced medical measures apply to a person who has already committed a criminal offense (long or short-term ). The procedure for compulsory accommodation is regulated by Ordinance No. 16 of the Health Insurance Act (2005) (5) on forensic psychiatric examinations and for execution of compulsory medical treatment by the Criminal Procedure Code (PPC) (6).

For the healthcare system, specifically for the physician, any interference with a forced nature is associated with the danger of exceeding the limits of its legal regulation.

In order to motivate the application of administrative coercive preventative nature, the danger (of crime) should be: obvious (plain, clear); real and concrete rather than abstract and supposed; Immediate, i. with a high risk of occurring immediately; significant, i. to threaten with severe consequences (7). In practice, mentally ill patients who threaten other people injure themselves very often $(8$, 9).

The promulgated Law in SG No. 70 of 10.08.2004, in force since 01.01.2005, with numerous amendments and supplements, the last of 05.08.2011, contains a differently organized model of procedure for placement of compulsory treatment compared to the previous one, which adequately regulates the guarantees against arbitrariness at the place of accommodation. Since 2009 The Ministry of Health has established and maintained a National Official Register of Persons with Mental Disorders.

Judicial control of forced medical measures for mentally ill patients is a guarantee against arbitrariness and subjectivism, but above all, humanity also requires the health administration to create administrative regulations to respect patients' rights in the process of medical care. Within the scope of psychiatric help, legal intervention is mainly confined to shortening the length of hospitalization and controlling the freedom of choice of the patient.

The psychiatrist's assessment of the medical standard is significantly facilitated when a risk assessment is to be carried out on a patient who is being compulsorily treated (by the order of the Criminal Code and the Penal Code) because "the patient has been antisocial and his only prospect is placement of treatment when not subject to any other sanction " (10).

According to the Swiss Code of Civil Procedure, Art. 16 (ZGB), effective from January 1, 2013, legally permissible is any person who is not deprived of his ability due to 
MIHAYLOVA $V$., et al.

minority and as a result of mental disorders, drug addiction or similar conditions, to act wisely (11). The view is that a large proportion of patients with mental illness isolated in psychiatric clinics can make decisions about their treatment such as patients with somatic diseases (12).

According to the Canadian Psychiatric Association, the leading ethical principle in medical law requires that incapacitated subjects should not be exploited as objects of research and deprived, based on the potential benefits of relevant research, or to suffer disproportionate harm from it (13).

The working therapeutical alliance between a doctor/psychologist and a patient occupies a priority function. Establishing the necessary interpersonal contact between the psychiatrist and the patient is a key point for the diagnosis and initiation of a treatment process marked by a creative seeking character. The relationship built on a specific sense of trust includes the components of the right to self-determination of the patient (in a number of cases to a certain extent) and a professional duty of the physician for medical care.

The principle of individualisation when the patient is informed about the disease and therapy is of particular importance here. The impulse for the psycho-hygienic approach to the patient is imbued in the duty of the psychiatrist. Given his pronounced sensitivity to injustice, his limited confidence and distraction by persons in whom he perceives pretense, the medical practitioner should avoid evasion of truth, deceit, lying, cunning. In spite of the fact that the paternalist model is often used in its weaker version, the doctor himself makes the best decision (due to the patient's condition, which does not allow him to make the most reasonable choice), he must be freed from any hint and elements of indulgence. The patient should see his or her healer similar, and his doctor suggests this position - a necessary prerequisite for unreserved confidence (14).

As with all other patients, and in the case of psychiatric patients, it is required besides information on the disease, research and treatment, and associated risks and dangers, as well as most patients, their consent. Moreover, even in forcibly detained patients, coercive treatment is often feasible.

In the past, a physician-patient relationship is built on a patriarchal-hierarchical relationship. Under the influence of psychotherapy, transformation takes place - the relationship grows into a working therapeutical alliance between the doctor and the patient, which builds on the patient's active co-operation. Often, the so-called a contractual model that governs the rights and obligations of both parties. The roles are stated for each stage of the treatment; through performance and non-compliance, the physician and patient are directly responsible for the outcome of the treatment. It is often used in drug addiction and treatment of other addictions.

For these patients, personal needs and needs are a central problem. The psychiatrist should be able to appreciate his or her own role as an impact and counteraction towards the patient in different personalities and disease states. Success often rests on an intense, and a less personal but rather distant, doctor-patient relationship. This relationship is favorably influenced by the empathy, by the conception and the imagination of the physician, who can be set in the role of the patient concerned; by this approach is able (in many cases) to impose his position on the basis of the biographical and dynamic background of the patient $(15,16,17)$. Strong power over the patient often affects positively, and the ethical point plays a major rolein this case.

A defining ethical principle in psychiatric activity is the respect for self-determination and autonomy of the patient and all actions are aimed at the patient's health well-being. The criteria for a valid informed consent are guiding: no coercion; an informed patient; competent patient. Minimal standards of selfdetermination have been identified: understanding the received information (even in partially destroyed cognitive processes); recognizing a particular situation and assessing its consequences; decision-making ability and its expression.

When determining the psychiatrist's reach of a severely ill, temporarily or permanently deprived of the ability to self-identify, the medics in psychiatry find themselves in a difficult moral and ethical dilemma. The doctor is in a tension-filled area - respect for the wishes of the patient, but also for his health welfare, and on the other hand, the duty and responsibility to the needy for help other self-defining persons in his family, as well as the interests of the institutions and society as whole.

Emphasis is also placed on the validity of informed consent and the position of "dissent", ie. the refusal of a corresponding examination or therapy, even when this 
refusal has negative consequences for their health condition, in accordance with (DGPPN) $(18,19)$. In order to be considered an optimal approach to a mentally ill in obtaining informed consent, it is necessary to use the so called subjective standard of the patient, i.e. what this patient needs to know and understand in order to make sense of his informed decision.

It is pointed out that psychiatric practice often leads to conflicting situations in which the expressed "free will" of the patient, expressed verbally or non-verbally (rejection, repelling hand movements, spitting pills, etc.), contradicts with a medical appointment aimed at the patient's health well-being. From this clinical point of view, the concept of selfdetermination acquires the significance of a central value problem in psychiatry. The alternatives and consequences resulting from the informed decision should be evaluated in accordance with their own life situation. In mentally ill, motivation for decisions often involves irrational, situational and interpersonal factors (20). This deviation between the will of the patient and his wellbeing should also be taken into consideration when the patient is fixed to restrict their mobility, as it poses a danger to others with their aggressiveness.

First published report on the informed consent position of the Canadian Psychiatric Association (CPA) in 1980, followed by a revised version (1988) and completed in 2015 $(21,21)$. Fundamental is the fact that psychiatrist realizes a situation-based approach to persons with pronounced mental disorders and their treatment, consistent with the patient's ability/capacity to make a decision. The revised version focuses on the need to consult colleagues and clinical psychiatric lawyers in every individual case. The Helsinki Declaration stipulates that the receipt of adequate informed consent in the case of mental or behavioral offenses is required by legally authorized representatives in accordance with applicable law (23). In circumstances where the informed consent procedure can not be performed (the patient's wishes for treatment are not fully known and clear), a decision maker should present the patient's wishes for treatment in his or her best interest. Psychiatrists should observe that in some circumstances the autonomy of a patient with mental illness needs to be balanced with his / her ethical obligations, and accordingly legislative requirements.
MIHAYLOVA V., et al. In all cases, the informed consent procedure starts from the first contact with the patient and continues until the end of the therapeutic interaction. It is specified that the patient's capacity within the procedure is compromised (unable to make a therapeutic choice) in a number of mental disorders, namely: visions and hallucinations; incl. diagnosed schizophrenia; acute stage of manicmelancholic psychosis; dementia; intellectual deficit; cognitive disorders; states of confusion; symptoms associated with severe disorders and mood instability; skull injuries $(24,25,26)$. If the value system, positions and decisions of the personality are unstable, contain contradictions and uncertainties, there is a good reason to reduce their competence. But: a patient with some mental abnormalities or disorders may be incompetent in some aspects but competent to decide on other aspects. For example, a patient with schizophrenia or paranoid aberrations may be competent to solve angina and other cardiac disorders; psychiatric counseling is indispensable in the presence of such situations.

Minimum standards to ensure the individual's ability to make decisions are limited to the requirement that the individual be able to: make his or her own choice and express it verbally; understands the relevant information disfigured in cognitive disturbances; recognize and understand the specificity of a particular situation and evaluate the consequences of it; the patient should have the capacity to process the rationally presented information (27).

The issue of notifying a patient whose cognitive abilities are satisfactorily preserved, the truth about the prognosis of a chronic progressive mental illness (eg Alzheimer's disease) (28) is inadequate clarified. Is there a response to managing the psychiatrist's uncertainty in reporting bad news in the spectrum between "productive" lie and destructive truth? Clarification is forthcoming!

Forced medical treatment should only be carried out at that time when all means of communication in forcibly detained patients has failed (28). Such forced treatment can last exceptionally for several days. Unfortunately, sometimes it takes more time for the patient to become aware of this need. The following questions arise: Is such kind of treatment is benefited of the patient? Is it necessary at all costs? Does such a coercive treatment not exacerbate the doctor-patient relationship? The opinion that therapy, empathy and love have to displace toxic drugs 
and electric shock in the treatment of mentally ill patients has questioning context $(29,30)$. Although patient care should be a priority for any treatment from a doctor's point of view, on the other hand, the patient's wishes should always be respected when he or she can understand the importance of the treatment, or recognize the concomitant effects and complications. Hence, the bipolar nature of the doctor's responsibility and the autonomy of the individual patient is confirmed here.

A number of authors continue to believe that one of the most effective therapies in psychiatry is electrical shock therapy (ETS), now called electro-convulsive therapy (ECT) $(31,32,33)$. Psychiatrists claim that a positive effect is achieved in the treatment of depression (misfortune, grief, sadness) due to unknown biological abnormalities in the brain or dysfunction in an immune response by provoking mental disorientation and memory loss (33). In some sources (including fiction, such as One Flew Over the Cuckoo's Nest ), the method is identified with an Inquisition, often causing severe brain damage, blasting bones during shock, and seizures accompanied by convulsions $(31,32,33)$. At the same time, many patients are tortured months and years of severe depression, with suicidal impulses, and antidepressant medical therapy rarely leads to improvement; some cases have been described in which antidepressant anti-shock therapy has a good and rapid effect (34). Many patients refuse this type of treatment due to the intense sufferings, sometimes ending with suicide. Few patients who are treated in this way are subjected to brief narcosis and muscle relaxation in the presence of an anesthesiologist.

Subjective patient experiences subjected to forced interventions such as physical restraint /fixation and isolation have a strong stressful character. Suffering is more pronounced than the forced use of medication. At the same time, it is noted that the use of psychopharmaceuticals against the will of the patient and hospitalization in a psychiatric institution should be explicitly ignored (35). Coercive measures are envisaged only if they are realized as: the last possible remedy for the purpose of the treatment; provide the necessary effect; are not associated with complications that outweigh the benefits of treatment. It is uncompromisingly highlighted that the use of coercive interventions, mechanical fixations and isolation, as well as the appointment /use of neuroleptics, should be severely limited and strictly require strict healthlegislative regulation $(36,37)$. The criticism of coercive measures generally converges to: "those affected can not resist the overpowering of over-aggressive psychiatry; the notion of care is paternalistic ", (which differs from some clauses in so-called global psychiatry) (38).

For that reason, coercive interventions are subject to strict legal regulation. Accidental imprisonment, called "involuntary psychiatric hospitalization" and "harmful psychiatric treatments" is similar to "psychosurgery" (39).

The position of a judicial institution in Germany (BGH) dated 11.10.2000, with the last supplement of 30.05.2009. exposes legal aspects of the use of psychopharmaceuticals, principally leading to: the prescribing of medication treatment against the will of the patient categorically deviates; the placement of psychiatrists in a hospital with a primary purpose of conducting medication therapy is inappropriate and unjustifiable (35).

It is also discussed the coercion of taking psychopharmaceuticals in an emergency situation with police intervention, as instructed by the legal guardian / counselor. The criticism of the Deutsche Gesellschaft für Psychiatrie und Psychotherapie, Psychosomatik und Nervenheilkunde eV (DGPPN) (under the pressure of protesters with mental disorders in remission) states that custody should not be placed above the principle for selfdetermination of affected subjects (18).

There is a clear view that enforcement measures should only be implemented as a last instrumentation and then be included if they are aimed at the ultimate goal of treatment that justifies their application and the effect they require and are not associated with stress and complications (40).

The ethical justification for enforcement (eg, restriction of freedom of movement and respectively movement through placement in a psychiatric facility, also fixation, isolation) and coercive treatment (eg medication against the will of the patient) are only ethically justified when incapacitated persons threaten specifically and at high risk their own health or life (self-harm) or the health and life of others. This situation can not be prevented by any other means, especially by trying to convince the patient of the danger of his behaviour and the need for treatment.

The positions thus formulated and interpreted in the legal-legal aspect allow the following summaries to be made, in a practical and applied plan: 
1. The point of reference of jurisprudence is that all adults are empowered to be mentally competent and legally competent to express a decision to conduct treatment unless otherwise defined by the court or reviewing / reviewing tribunal

2. The role of law in the ethical evolution of decisions in psychiatry, and in particular in the identification of ethical issues related to autonomy, well-being, harm, decision-making by the patient, is emphasized. Psychiatry requires, above all, empathy in care; the treatment itself has a subordinating effect.

3 . The bipolar nature of a doctor's professional duty to ensure the good / good of the patient and the respect for his will and his right to selfdetermination is highlighted in psychiatry as a fundamental bioethical configuration.

4. An initiative of the administration of the healthcare facility to provide a legal counsel to the patient (the person may be an administrative or medical employee without special legal training but with experience in the health facility and with high moral-ethical qualities, always acting on the patient's side advocate or counselor).

5. Introduce additional texts to the Health Act concerning the limitations of the rights of patients with psychiatric disorders in the following areas: protecting the patient from the public and upgrading the legal guarantees for involuntary hospitalization in psychiatric establishments; legalizing additional options for outpatient (voluntary and involuntary) treatment; the hospitalization of the mentally treated patients in the presence of necessary indications to be transformed from the psychiatric to the general hospitals; restrictions on persons with psychiatric disorders to the general health care system.

It is suggested that the process of optimization of health care requires both a rethinking of ethical-deontological principles and the examination of existing legal provisions. A prerequisite is the introduction of standards that ensure the observance of both administrative and moral-ethical principles and rules.

\section{REFERENCES}

1. World Health Organization. Mental health: strengthening our response, 2010. Available at:

http://www.who.int/mediacentre/factsheets/fs 220/en/. Accessed October 6, 2014.

2. European Convention for the Protection of Human Rights and Fundamental Freedoms (promulgated SG 80/1992).

3. Bulgarian Constitution, Article 5, paragraph 4.
MIHAYLOVA V., et al.

4. Instruction No. 1 on Occupational Health Activities of persons in psychiatric hospitals, promulgated SG, issue 48/2004.

5. Ordinance No. 16 of the Health Insurance Act on forensic psychiatric examinations, 2005.

6. Compulsory medical treatment by the Criminal Procedure Code (PPC), 2012.

7. Valchev, A., Panev, B., Donchev, P., Tomova, S., Videnova, F. Medical law and deontology. Publ. "Medicine and Physical Education", Sofia, edited by P. Donchev, 184 p., 1992.

8. Baltov, M. Forensic aspects of suicide in the Plovdiv region for the period 2000-2009., author' $\mathrm{s}$ abstract for $\mathrm{PhD}$ thesis, Plovdiv, 2013.

9. Raykova, E., Bivolarski, I., Peshev, Zh. Dynamics of suicide rates in the regions of Plovdiv, Kardzali and Smolyan in the Republic of Bulgaria over the period 2000 2009. Eurasian Union of Scientistist, Medical Sciences, 5 (14): 6-9, 2015.

10. Medical Standard "Psychiatry", approved by Ordinance No. 24 of July 7, 2004 and Article 146, Paragraph 1 of the Harmonization Act.

11. Schweizerishes Zivilgesetzbuch(ZGB), (Fassung gemäss Ziff. I 2 des BG vom 19. Dez. $2008 \quad$ (Erwachsenenschutz, Personenrecht und Kindesrecht), in Kraft seit 1. Jan. 2013 (AS 2011 725; BB1 2006 7001).

12. Amer, AB. Informed Consent in Adult Psychiatry. Oman Medical Journal. 2013;28(4):228-231. doi:10.5001/omj.2013.67.

13. Canadian Psychiatric Association (CPA) position paper on Consent in Psychiatry in 1980, revised version in 1988.

14.Lehmann, P. Ethik Probleme in der Psychiatrie Praxis. Lange Liste der Verstöße. Wissen Psychosozial, Heft, 16, 2014.

15. Appelbaum, PS. Clinical practice. Assessment of patients' competence to consent to treatment. $N$ Engl J Med 2007. Nov;357(18):1834-1840 10.1056/NEJMcp074045[PubMed] [Cross Ref].

16.Lepping, P. Consent in Psychiatry:an ethical review. PsychiatrBull 2003;27:285-289 $.10 .1192 / \mathrm{pb} .27 .8 .285$ [Cross Ref]

17. Rosoff, AJ. Informed consent (a guide for health care providers). Rockville, Maryland: Aspen Publications, P14, 1981.

18. Deutsche Gesellschaft für Psychiatrie und Psychotherapie, Psychosomatik und Nervenheilkunde e.V. (DGPPN)1, Berlin. Achtung der Selbstbestimmung und Anwendung von $\mathrm{Zwang}$ bei der Behandlung psychisch erkrankter Menschen. Eine ethische Stellungnahme der DGPPN. Nervenarzt 2014 - [jvn]: [afp]-[alp] DOI 10.1007/s00115-0144202-8 Online publiziert: [OnlineDate] (C) Springer-Verlag Berlin Heidelberg 2014 
19.Pinals, A. Informed Consent: Is Your Patient Competent to Refuse Treatment? Current Psychiatry, 8(4):33-43, 2009.

20.Koch Hans-Georg, Reiter-TheilStella, Helmchen Hanfried. Informed Consent in Psychiatry: European Perspectives of Ethics, Law and Clinical Practice, IST ed. BadenBaden: Nomos Verl-Ges. Germany, 1996.

21.Canadian Psychiatric Association (CPA) position paper on Consent in Psychiatry in 1980, revised version in 1988.

22.Neilson, G., Chaimowitz, G. Informed Consent to Treatment in Psychiatry. Canadian Journal of Psychiatry Revue Canadienne de Psychiatrie, 60(4):1-11, 2015.

23. Declaration of Helsinki: Recommendations Guiding Medical Doctors in Biomedical Research Involving Human Subjects." Helsinki, Finland: 18th World Medical Assembly, 1964. Reprinted in: Katz, Jay. Experimentation with Human Subjects. New York: Russell Sage Foundation, 1972, pp. 312-313. The most recent (October, 2000) version is available online at: http://www.wma.net/e/policy/17c.pdf

24. Amer, AB. Informed Consent in Adult Psychiatry. Oman Medical Journal, 28(4):228-231, 2013, doi:10.5001/omj.2013.67.

25. Brahams, D. Informed Consent, Reports of the $8^{\text {th }}$ World Congress on Medical Law, Praag, t.II, 130-134,1988.

26. www.zdrave-bg.eu /depression/. Bivolarski, I.

27. Stein, V. »Mit dem Rücken zur Wand. Ein Ratgeber - So setze ich mein Recht im Arzthaftungsprozess durch! «, Frankfurt am Main: VAS Verlag für Akademische Schriften Truöl, H.-J. (2012): »Aktivisten nutzen Ministerbesuch für Protest gegen Zwangsmedikation«, in: Badische Zeitung vom 24. Juli 2012, Online-Ausgabe; www.badische-zeitung.de/emmendingen/ aktivisten-nutzen-ministerbesuch-fuerprotest-gegen-zwangsmedikation-61959736.html.

28.Lehmann, P. "Frühe Warnzeichen für chronische oder tödlich verlaufende neuroleptikabedingte Erkrankungen", in: Allegro - Magazin psychisch beeinträchtigter Menschen, Nr.1,S.34-38, 2012;im Internetunter www.antipsychiatrieverlag.de/ar tikel/gesundheit/pdf/warnzeichen-

allegro.pdf (Download am 2.11.2013); und in: Mitgliederrundbrief des Bundesverbands Psychiatrie-Erfahrener (BRD), 2014, Nr. 1, S. 16-19.

29.Breggin, P.R. Toxic Psychiatry: Why Therapy, Empathy, and Love Must Replace the Drugs, Electroshock, and Biochemical Theories of the "New Psychiatry" (St. Martin's Press, New York, 1991).
30. www.zdrave-bg.eu Bivolarski, I.

31. Breggin, P.R. Electroshock: Its Brain Disabling Effects (Springer Publishing Co., New York, 1979).

32. Leonard Roy Frank (editor), The History of Shock Treatment (self-published, San Francisco, 1978).

33. Thomann, Ph., Wolf, R. Nolte, H. at all. Neuromodulation in response to electroconvulsive therapy in schizophrenia and major depression. Basic Translational and Clinical Research in Neuromodulation, Volume 10, Issue 3, Pages 637-644, 2017.

34. Yrondi, An., Sporer, M., Péran, P., Schmitt, L., Arbus, Ch., at all. Brain Stimulation: Basic, Translational, and Clinical Research in Neuromodulation, Vol. 11, Issue 1, p2951, Published online: October 19, 2017.

35. Urteil des Bundesgerichtshofs vom 11.10.2000 (BGH Beschluss XII ZB 69/00), Vootext auch unter http: //letxtius. com/2000,2337, letzter Zudriff am 30.05.2009.

36. Aderhold, V. »Neuroleptika zwischen Nutzen und Schaden. Minimale Anwendung von Neuroleptika - $\quad$ ein Update« unveröffentlichtes Manuskript vom September 2010; www.bgt-ev. de/fileadmin/Mediendatenbank/Themen/Psyc hopharmakadebatte/Aderhold_Neuroleptika_ update.pdf.

37. Lehmann, P. »Die Einnahme antipsychotischer Medikamente führt oft zum Suizid. Warum interessiert niemanden, dass so viele Psychiatriebetroffene an der Behandlung sterben? «, in: Verweigerte Selbstbestimmung in der Behandlung psychiatrischer Patientinnen und Patienten 104 Pohl, I. (Hg.): »Schluss mit Lobbyismus! 50 einfache Fragen, auf die es nur eine Antwort gibt«, Frankfurt am Main: Westend Verlag, S. 164-167, 2012.

38. Katz, L., Craig \& P Lahey, Timothy \& Campbell, Hilary. An Ethical Framework for Global Psychiatry. Annals of global health. 80. 146-151, 2014, 10.1016/j.aogh.2014.04.002.

39.Lehmann, P. Stellungnahme zur Gewaltbereitschaft der Psychiatrie für die Zentrale Ethikkommission bei der Bundesärztekammer, Arbeitskreis »Zwangsmaßnahmen in der psychiatrischen Versorgung«, Berlin, 4. Mai 2012, in: Leuchtfeuer - Journal des Landesverbandes der Psychiatrie-Erfahrenen Rheinland-Pfalz, Sonderausgabe, S.9-24,2012.

40.B VerfG, 2 BvR 882/09 vom 23.3.2011, Absatz-№ http://www.bverfg.de/entscheidungen/rs2011 0323 2bvr088209.html 